\title{
Creative Teaching in Art: Content Analysis and Evaluation of Training Manuals Formed by Students
}

\author{
Maria Kampouropoulou ${ }^{1}$, Persa Fokiali ${ }^{2}$, Ioanna Efstathiou ${ }^{1} \&$ Efstathios Stefos ${ }^{1}$ \\ ${ }^{1}$ Department of Primary Education, University of the Aegean, Rhodes, Greece \\ ${ }^{2}$ Department of Preschool Education Sciences and Educational Design, University of the Aegean, Rhodes, Greece \\ Correspondence: Efstathios Stefos, Department of Primary Education, University of the Aegean, Dimokratias 1, \\ Rhodes 85100, Greece. Tel: 30-224-109-1451. E-mail: estefos@aegean.gr
}

Received: November 7, $2013 \quad$ Accepted: December 3, 2013 Online Published: January 16, 2014
doi:10.5539/res.v6n1p1
URL: http://dx.doi.org/10.5539/res.v6n1p1

\begin{abstract}
The goal of this study is to investigate and evaluate training manuals created by students, like exploration of their views on how promoting children's cultural heritage in Primary schools. The study concerns the degree of completeness of the training manuals according to their content and functionality within aesthetic presentation, creativity, responsiveness to pedagogical objectives, etc. They were created by students studying in the Department of Primary Education of the University of the Aegean (fourth year of training) and they completed their work for the course "Artistic Education and Creations of Artistic forms". The issue was: The Palace of the Grand Master, history and environment of the medieval city of Rhodes. In order to extract the research results, we used statistical software SPSS v.17 offered by the School of Humanities of the University of the Aegean.
\end{abstract}

Keywords: art, content analysis, critical discourse analysis, evaluation of training manuals

\section{Introduction}

"Art Education and Creative Thinking" as a lesson, introduces students in a course that negotiates both the relationship between Cultural heritage and Art Education and the relationship between modern Art and Art Education in Primary school. These axes are related to the use of Art -old and modern- and to cultural heritage in a composition of cultural products using creativity and various visual forms. Students trained to study topics related to the cultural heritage by getting information and learning how to translate this information into new creations which may be educational material for children in Primary Education. Meanwhile, they enrolled interdisciplinary activities, seeking a variety of materials, using new technologies in order not only to create educational material, but also to prove how important is teaching Art in schools so that cultural heritage can be promoted (Fokiali et al, 2003). The whole process, they were invited to follow, was exactly the same they would choose as future teachers in order to teach the lesson of Artistic Education in school.

\section{Method}

The rapid social and technological changes have resulted in revised pedagogical views on how to approach the knowledge, its transmission and generally the environment of such an educational effort. Learning outcomes are dependent upon the environment, prior knowledge, values and attitudes of students (Plakitsi \& Kokkotas, 2005). It is mentioned above that the main axes of Art Education course students were trained into is the relationship between Cultural heritage and Art Education and the relationship between modern Art and Art Education in Primary school.

The thematic framework of the first pillar related to cultural heritage and artistic education is the importance of creative synthetic work in Arts and the Pedagogical/Educational applications that Art offers in cultural education. The cycle of the University lectures approaches the development of artistic expression in school age by creating complex tasks and enables the combination between traditional and new technologies and also conventional ways of artistic techniques. The steps followed are:

First Stage: At this stage the basic goal of the lectures is for the students to meet cultural heritage, the importance of its conservation and the use thereof in any way but, mainly through Art Education. The main purpose is to teach students how to study data and issues of cultural heritage and also how to translate them by transforming different visual techniques in new creations. 
Second Stage: At this stage students practice on designing and creating educational manuals accompanied with texts, suitable for teachers and children in order to use them for their initiation to cultural heritage through a pedagogical way.

Third Stage: At this stage are explored the ways of integrating the first two stages in school curricula and their implementation by the students in teaching level, beyond the research.

The thematic framework of the second axis, - the relationship between modern Art and Educational Art- in Primary Schools, is Artistic Education creations formats. At this stage students are asked to create themselves training manuals attracted to students of Primary schools, suitable for them to learn with questions, exercises, activities appropriate to their age.

For the evaluation of training manuals we used three sections of criteria

(a) Content - Functionality.

(b) Artistic Expression and Aesthetic Presentation.

(c) Creativity.

The efficacy (effectiveness) of a training manual is being studied worldwide and is based, inter alia, in the pedagogical research teaching effectiveness. The subject of the research is whether the learners derive knowledge and learning elements, if there is response (resposiness), i.e. if the trainees are covered in needs and in terms of time. Jewett argues that the educational process is essentially a service related to teaching and that it should be the subject of study and research on learning outcomes to replace or improve old teaching methods with new ones (Jewett, 1996).

The method was used is a combination between content analysis and critical discourse analysis. Both of the methods are flexible and they drive someone further to other types of analysis. In particular, the critical analysis thinking can entrance the types of qualitative analysis (Wilbraham, 1995). Each training manual was evaluated separately for each metric criterion using the Linker scale. Many scholars have expressed different views for the criteria as for the content. Chiappetta (Chiapetta et al., 1993) focused on understanding the scientific knowledge provided by the training manuals, the incentives provided to further search for scientific knowledge, the cultivation and development of critical thinking and finally the interactive relationship between Science, Technology and Society. Also others believe that the content of training manuals should be evaluated based on the development of intelligence / thinking of students, surpassing the particular teaching process itself, to develop abilities and skills in metacognitive level. Finally, some researchers believe that the content of textbooks should be assessed for their impact in shaping character, life attitudes and perceptions of students (Johnsen, 1993). The choice of the various criteria is intended to identify quality indicators of training manuals created by the students. Richaudeau believes that training manuals should be evaluated for content, contents' communication skills with students, their organization and their adaptation to the needs and age of children. Also are evaluated for the aesthetic image, materiality and generalease of usability. In this study we will present the Unit of Creativity as criteria for all training manuals.

\section{Creativity}

There have been many definitions of creativity as it is a simple process to solve problems or find them. It describes an attempt for exploration, experimentation and spiritual process in order to obtain serious/educated decisions (Piaget, 1960). Bruner argues that it is an action through which results in a surprisingly effective (Bruner, 1966). The creative ability is related to personality of each individual, his creative features and production. It is also directly linked to the imagination which enables the composition and presentation of different thoughts. Guilford cites as basic characteristics of creativity, the fluency of thought, flexibility of thought, originality, analysis - composition, transformation, edit - output, and organization - complexity.

\subsection{The Characteristics of Creative Thinking According to Guilford}

Fluency of thought [cognitive fluency (fluency of ideas, words, associations, expression)]: is the ability of an individual to the solutions of given problems by combining to them already known solutions or by attempting to gather information about the creative process. With the fluency of thought are also connected the ideas a person might have and the combinations he makes in order to pass in several suggestions. It is an ability of an individual according to the number of production of quantity ideas or associations, correlations and it is determined both by the number and the speed with which the presented concepts or ideas are presented. The difference between the creative mind of a "limited" mind is focused on the fact that creative mind "is flooded" with many ideas, most of which are usually original and ultimately useful. 
Guilford states that the power of fluency is characterized by three factors:

a) The power of an idea conception and the birth of many which can cope with the mental needs.

b) The associative fluency, meaning that through the occasion of an idea to produce a lot of relationships or associations, between the stimuli or to perform recall and creating performances which are related to further production as possible of both transport metaphors, similarities, analogies and symbolisms.

c) The expressive power, i.e. the ability of a person to compose proposals through the use and placement of suitable, but limited number of words.

d) The power of words, a persons' ability to produce a large number of words with suffix -driven or the first part of the word, without regarding their conceptual content.

Flexibility of thought: It is the ability of a person to be oriented to new situations, i.e. it has the ability to rotate a figure of thought to another. It may develop a variety of views through different approaching «streets» for a problem. A prerequisite is the focus and address of a topic from many sides, the change in thinking by creating many different benchmarks. Flexibility is divided into two categories:

a) The spontaneous flexibility, i.e. the ability of an individual to reproduce various ideas, directing thought to mark simple information in a multitude of other ideas. For example a person who has flexibility, produces spontaneous ideas with respect to a material, such as paper, starting from the shape and then the weight, color, texture, etc. i.e., showing flexibility in the direction of thought with the individual initiative. (Example spontaneous flexibility is finding a particular time as much use as possible of an object).

b) The adoptive flexibility (adaptive): a person's ability to direct his thinking in solving various problems based on one adopted method and on the form of the problem. Considered necessary in solving problems those require the exclusion of use of old known and established ways of thinking and application of new methods to innovative / unusual directions. Such a person may be, for example, in a simple shape with Lego bricks to shift some of them and give a completely different shape to the object.

Originality of thought: Originality is the ability a person has to redefine, create, and organize again something in a completely different way than other people. His works and innovations are conceptually ideas but also to the unexpected, curious and entertaining part of our ideas. To be considered a masterpiece as original it should be a synthesis of pre-existing knowledge and experiences that have not been copied, but transformed by bringing the unique personal character of the person who invented it. Although statistically originality is limited, however investigations of Malzman, Mednick, Wallach - Kogan demonstrated that it is possible to achieve originality through proper exercise in some categories and it can be extended to others.

Analysis - Composition: The ability of decomposition - analysis may have a person as well as the separation of parts forming a whole. This way of thinking focuses on each part separately from the whole and makes possible links between them. Therefore, the operation of the analysis is closely intertwined with the composition. A person with creative thinking is able to combine several components together to create a whole through a process that is not mechanical but it is characterized as qualitative production.

Transformation: Refers to the ability a person has to be able to give a different interpretation or perception of the use of an object or part of it, putting aside the hitherto known and adapt to new modes of use. Therefore various experiences, ideas, images, performances etc. ' classified ' in this way, they form "clusters" according to the relationship that governs them towards an internal structure of attitudes and knowledge [rebuild redefinition (redefinition)]. So, we talk about a reorganization of already organized groups in a new or a moderation from an object to another that has a different use, operation, and even form. The same can happen with an incomplete initial idea, theme, story, which a creative person can process and deliver something integrated whole that may be relevant and attractive.

Edit - Output: Delivery is the ability a person has and manages to carry out, to give form to ideas. In the process of editing a function of divergent thought, it is possible for the ideas to expand, to grow, to take shape and form and complexity can be produced.

Organization- Complexity: Is the ability a person to be able to plan, organize various information which is known and create new specific situations through a specific course of processing such information. One such feature distinguishes a person who can design and organize a music concert perfect starting simply by recording a short speech program of the concert (Guilford, 1952).

\section{Evaluation of Teachers Manuals}

Each training manual was evaluated separately for each metric criterion with the use of the Linker scale as 
follows:

1. Not at all satisfied

2. Slightly satisfied

3. Somewhat satisfied

4. Very satisfied

5. Extremely satisfied.

Table 1. Fluency thinking

\begin{tabular}{lcc}
\hline & Frequency & Percentage \\
\hline Not at all satisfied & 3 & $4.62 \%$ \\
Slightly satisfied & 9 & $13.85 \%$ \\
Somewhat satisfied & 18 & $27.69 \%$ \\
Very satisfied & 9 & $13.85 \%$ \\
Extremely satisfied & 26 & $40.00 \%$ \\
\hline Ensemble & 65 & $100.00 \%$ \\
\hline
\end{tabular}

As shown in Table 1 and Figure 1, during the evaluation of the criterion "fluency thinking" $4.62 \%$ of training manuals was "Not at all satisfied", the $13.85 \%$ "Slightly satisfied" to $27.69 \%$ "Somewhat satisfied", the $13.85 \%$ "Very satisfied" and 40.00\% " excellent "Extremely satisfied".

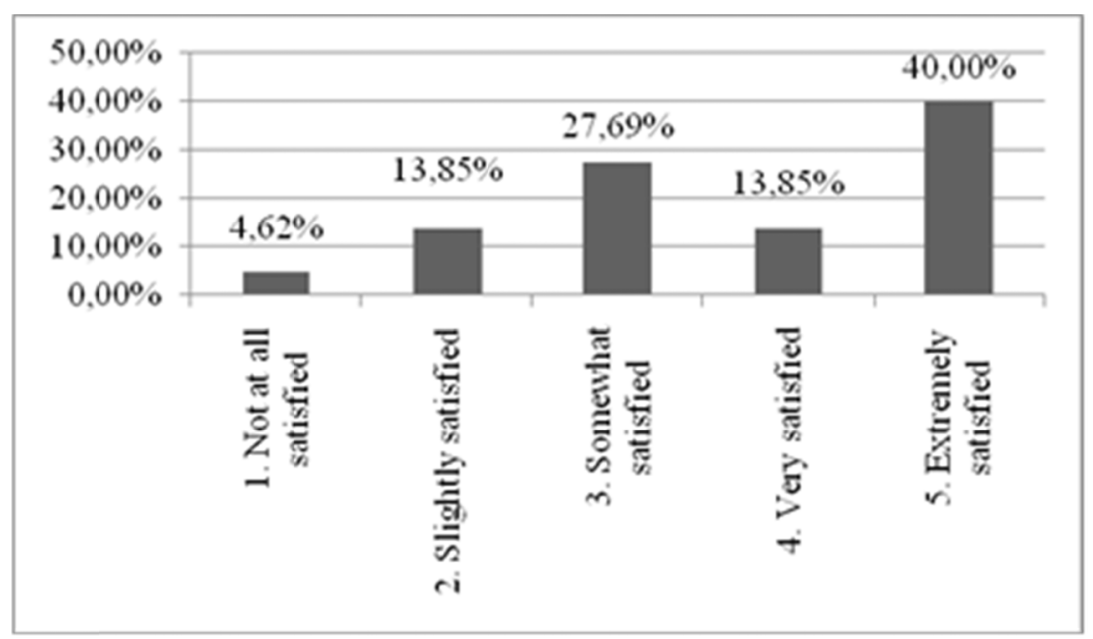

Figure 1. Fluency thinking

Table 2. Flexibility thinking

\begin{tabular}{lcc}
\hline & Frequency & Percentage \\
\hline Not at all satisfied & 3 & $4.62 \%$ \\
Slightly satisfied & 9 & $13.85 \%$ \\
Somewhat satisfied & 17 & $26.15 \%$ \\
Very satisfied & 10 & $15.38 \%$ \\
Extremely satisfied & 26 & $40.00 \%$ \\
\hline Ensemble & 65 & $100.00 \%$ \\
\hline
\end{tabular}

As shown in Table 2 and Figure 2, during the evaluation of the criterion "fluency thinking" $4.62 \%$ of training manuals was "Not at all satisfied", the $13.85 \%$ "Slightly satisfied" to $26.15 \%$ "Somewhat satisfied", the $15.38 \%$ "Very satisfied" and $40.00 \%$ " excellent "Extremely satisfied". 


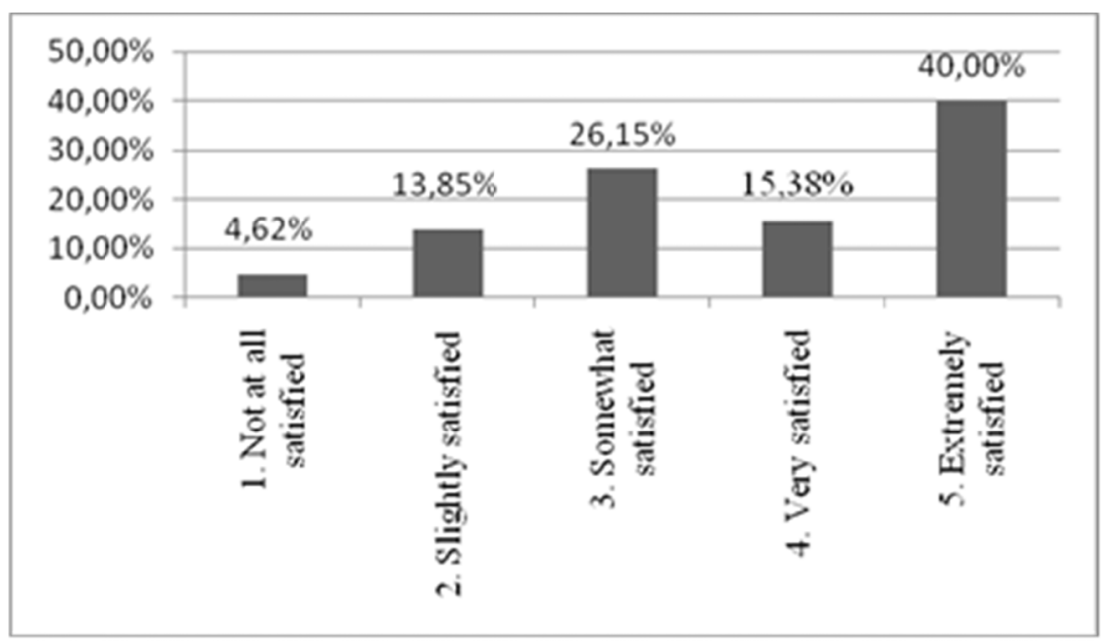

Figure 2. Fluency thinking

Table 3. Originality of thought

\begin{tabular}{lcc}
\hline & Frequency & Percentage \\
\hline Not at all satisfied & 3 & $4.62 \%$ \\
Slightly satisfied & 9 & $13.85 \%$ \\
Somewhat satisfied & 16 & $26.62 \%$ \\
Very satisfied & 11 & $16.92 \%$ \\
Extremely satisfied & 26 & $40.00 \%$ \\
\hline Ensemble & 65 & $100.00 \%$ \\
\hline
\end{tabular}

As shown in Table 3 and Figure 3, during the evaluation of the criterion "fluency thinking" $4.62 \%$ of training manuals was "Not at all satisfied", the $13.85 \%$ "Slightly satisfied" to $26.62 \%$ "Somewhat satisfied", the $16.92 \%$ "Very satisfied" and 40.00\% " excellent "Extremely satisfied".

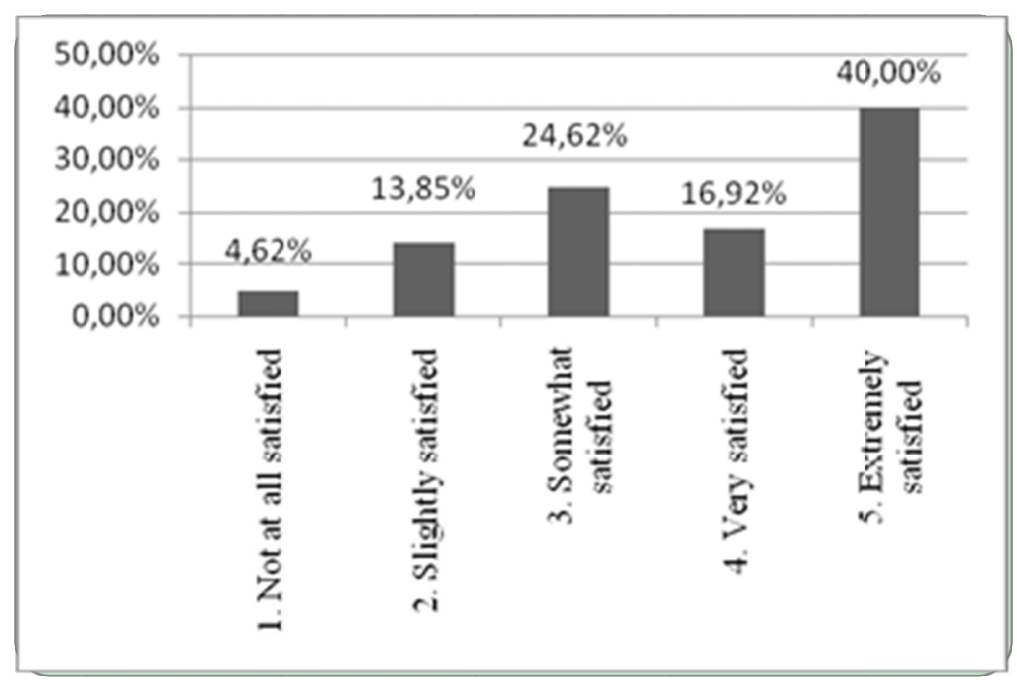

Figure 3. Originality of thought 
Table 4. Analysis - Composition.

\begin{tabular}{lcc}
\hline & Frequency & Percentage \\
\hline Not at all satisfied & 1 & $1.54 \%$ \\
Slightly satisfied & 8 & $12.1 \%$ \\
Somewhat satisfied & 21 & $32.31 \%$ \\
Very satisfied & 11 & $16.92 \%$ \\
Extremely satisfied & 24 & $36.92 \%$ \\
\hline Ensemble & 65 & $100.00 \%$ \\
\hline
\end{tabular}

As shown in Table 4 and Figure 4, during the evaluation of the criterion "fluency thinking" $1.54 \%$ of training manuals was "Not at all satisfied", the $12.1 \%$ "Slightly satisfied" to $32.31 \%$ "Somewhat satisfied", the $16.92 \%$ "Very satisfied" and 36.92\% " excellent "Extremely satisfied".

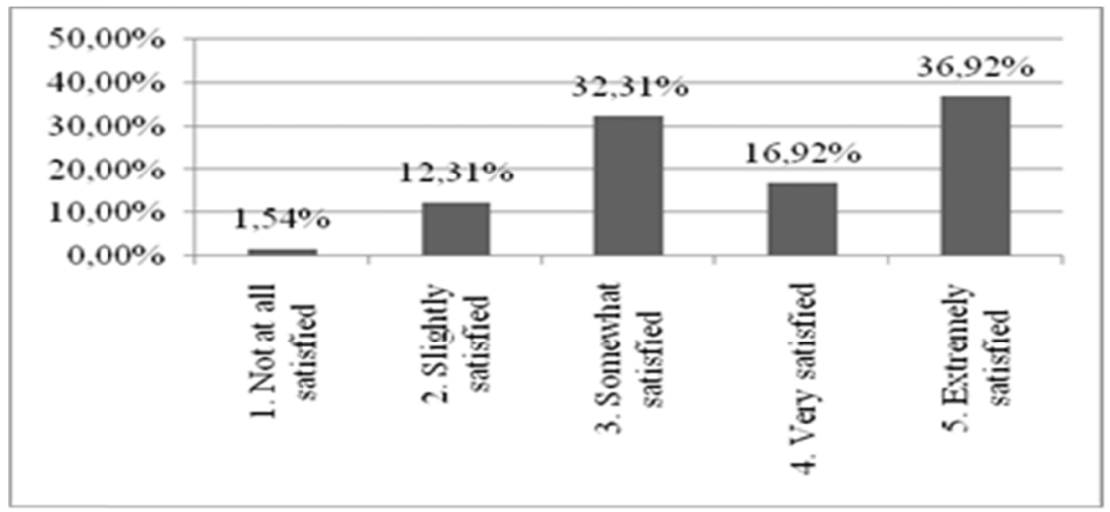

Figure 4. Analysis - Composition

Table 5. Transformation

\begin{tabular}{lcc}
\hline & Frequency & Percentage \\
\hline Not at all satisfied & 3 & $4.62 \%$ \\
Slightly satisfied & 7 & $10.77 \%$ \\
Somewhat satisfied & 20 & $30.77 \%$ \\
Very satisfied & 9 & $13.85 \%$ \\
Extremely satisfied & 26 & $40.00 \%$ \\
\hline Ensemble & 65 & $100.00 \%$ \\
\hline
\end{tabular}

As shown in Table 5 and Figure 5, during the evaluation of the criterion "fluency thinking" 4.62\% of training manuals was "Not at all satisfied", the $10.77 \%$ "Slightly satisfied" to $30.77 \%$ "Somewhat satisfied", the $13.85 \%$ "Very satisfied" and 40.00\% " excellent "Extremely satisfied".

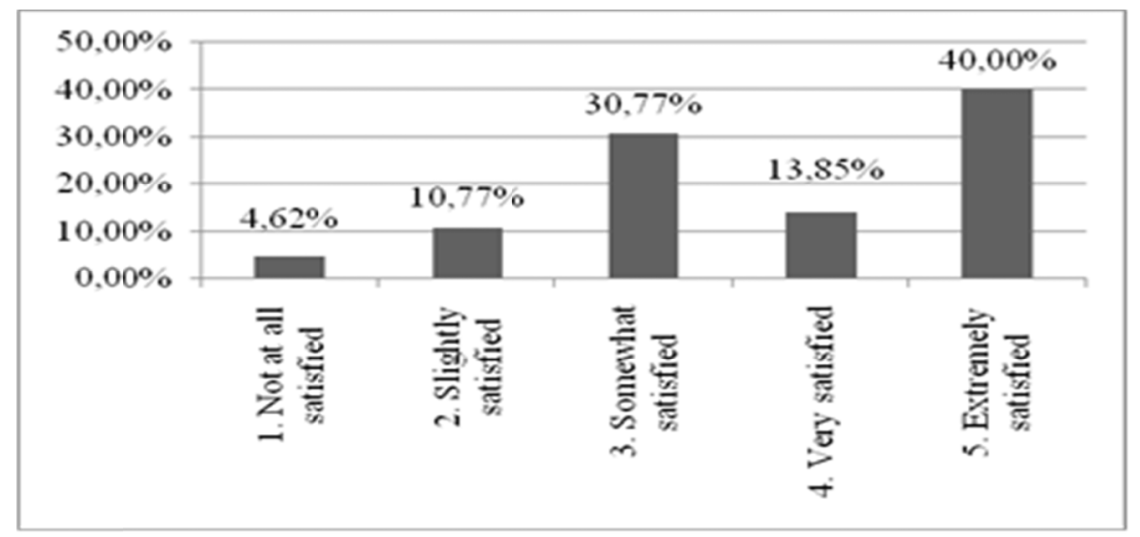

Figure 5. Transformation 
Table 6. Edit - Output

\begin{tabular}{lcc}
\hline & Frequency & Percentage \\
\hline Not at all satisfied & 3 & $4.62 \%$ \\
Slightly satisfied & 6 & $9.23 \%$ \\
Somewhat satisfied & 18 & $27.69 \%$ \\
Very satisfied & 12 & $18.46 \%$ \\
Extremely satisfied & 26 & $40.00 \%$ \\
\hline Ensemble & 65 & $100.00 \%$ \\
\hline
\end{tabular}

As shown in Table 6 and Figure 6, during the evaluation of the criterion "fluency thinking" 4.62\% of training manuals was "Not at all satisfied", the $9.23 \%$ "Slightly satisfied" to $27.69 \%$ "Somewhat satisfied", the $18.46 \%$ "Very satisfied" and 40.00\% " excellent "Extremely satisfied".

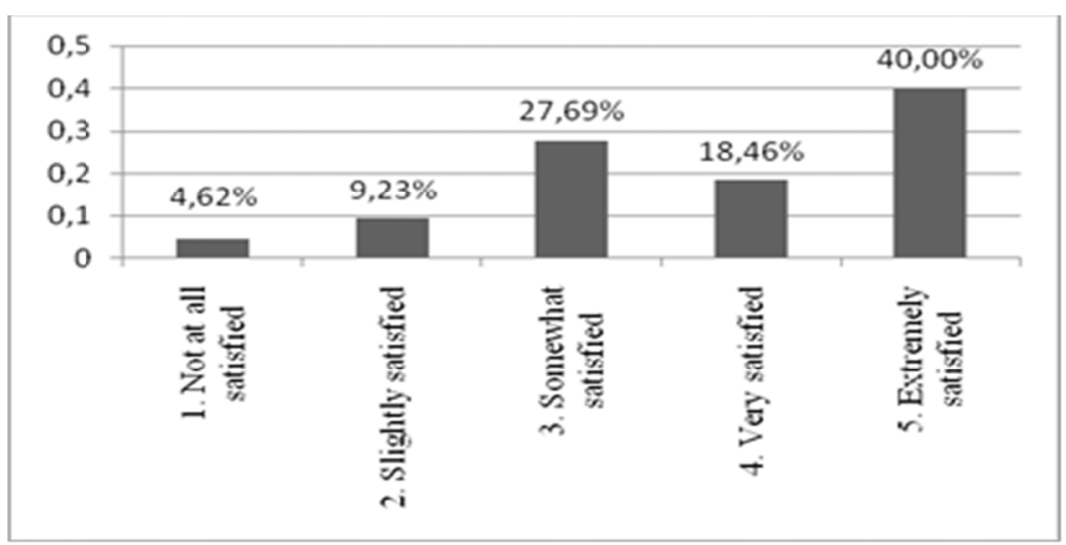

Figure 6. Edit - Output

Table 7. Organization - Complexity

\begin{tabular}{lcc}
\hline & Frequency & Percentage \\
\hline Not at all satisfied & 3 & $4.62 \%$ \\
Slightly satisfied & 7 & $10.77 \%$ \\
Somewhat satisfied & 16 & $24.62 \%$ \\
Very satisfied & 13 & $20.00 \%$ \\
Extremely satisfied & 26 & $40.00 \%$ \\
\hline Ensemble & 65 & $100.00 \%$ \\
\hline
\end{tabular}

As shown in Table 7 and Figure 7, during the evaluation of the criterion "fluency thinking" 4.62\% of training manuals was "Not at all satisfied", the $10.77 \%$ "Slightly satisfied" to $24.62 \%$ "Somewhat satisfied", the $20.00 \%$ "Very satisfied" and 40.00\% " excellent "Extremely satisfied".

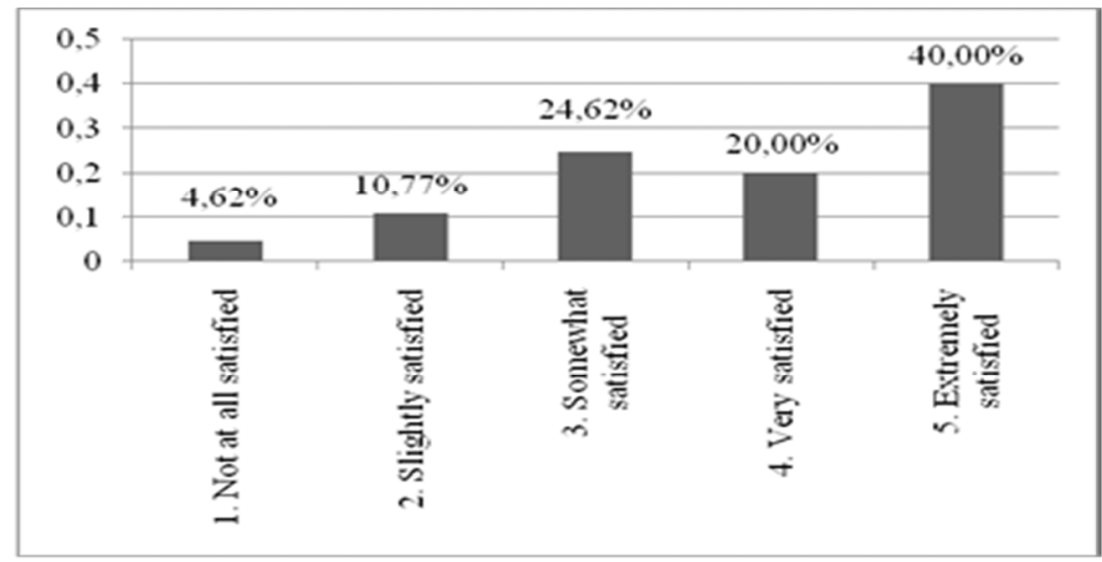

Figure 7. Organization- Complexity 


\section{Conclusions}

Research and evaluation was based on the production of quality data by observing the written texts and researching, visual material contained in the training manuals (Mason, 2011). Through utilization ie of multivariable analysis and completeness of the information provided by the textures, such as content, structure organization, pedagogy and teaching fitness, aesthetic presentation, artistic expression, etc. The efficacy (effectiveness) of a training program is being studied worldwide and is based inter alia, research on pedagogy teaching effectiveness. Whether they are the learners derive knowledge and learning elements, if no response (responsiness), i.e. if the trainees are covered in needs and in time. Arts affects children's lives and students, studying to be teachers, must increase their creativity in any way, especially by using the right training manuals (Kampouropoulou et al., 2011). Creativity education develop those cognitive abilities that allow children to be able to analyze, describe, assess, interpret and also realize that culture and Art are two interrelated elements (Kampouropoulou-Savvaidou, 2007). Since training manuals created by the students were based not only on written texts, but also on everything mentioned above, we tried in our research to develop a "dialogue" between research / evaluation in order to move in a "research cycle", i.e, in understanding the text and the context in which they were created (Scott, 1990).

The goal of this study was to investigate and evaluate training manuals created by students studying in the Department of Primary Education in the University of the Aegean for the course "Artistic Education and Creations of Artistic forms" on how promoting children's cultural heritage in Primary schools. The evaluation showed that the majority of the Educational Manuals can be used by children in order to discover information about the Medieval city if Rhodes, the great Master and his Palace, but also they proved that the course they followed was very important to them, as they learn how to use loads of ideas, combine them, transform them and organize their material to a Manual cognitively useful and aesthetically attractive to children in Primary Education. Content analysis thus, maintaining the positive aspects of quantitative research gave more importance to a thorough investigation of the material by developing a set of techniques for the systematic analysis of texts. So it really kept the benefit of quantitative analysis but progressing and further interpretive use of them (Mayring, 2000).

\section{References}

Bruner, J. S. (1966). Toward a theory of Instruction. Cambridge Mass: Harvard University Press.

Chiappeta M., Eugene L., F. D. A., \& Sethina-Godrej H. (1991). A Method to Quantify Major Themes of Scientific Literacy in Science Textbooks. Journal of research in science teaching, 28(8), 713-725. http://dx.doi.org/10.1002/tea.3660280808

Fokiali, P., Kampouropoulou, M., \& Konsolas, M. (2003). Sustainable Development, Art and linguistic communication. Teaching children of primary school to plan the future of their country. Pedagogikos Logos.

Guilford, J. P. (1952). Some recent findings on thinking abilities and their implications. International Bulletin, U.S. Air Force, 3(3), 61.

Jewett, F. (1996). Case Studies in Evaluating the Benefits and Costs of Mediated Instruction/Distributed Learning. California State University. Retrieved from http://www.calstate.edu/special_projects/mediated_instr/case_study_manual.html

Johnsen, B. E. (1993). Textbooks in the kaleidoscope - A critical survey of literature and research on educational texts. Oslo: Scandinavian University Press.

Kampouropoulou, M., Fokiali, P., Athanasiadis, I., \& Stefos, E. (2011). Teaching Art using Technology: The views of High School students in Greece. Review of European Studies, 3(2), 98-109. http://dx.doi.org/10.5539/res.v3n2p98

Kampouropoulou-Savvaidou, M. (2007). New Technologies and Education Sciences. Athens. Metaichmio.

Kokkotas, V., \& Plakitsi, K. (2005). Time for education: Ontology, epistemology and discursiveness in teaching fundamental scientific topics. Presented to 1st International Conference of International Society for Cultural and Activity Research (I.S.C.A.R.), Seville, Spain, 2005. Book of Abstracts (pp. 785-786).

Mason, J. (2011). Conducting qualitative research (pp. 11-139). Athens, Pedio.

Mayring, P. (2000). Qualitative Content Analysis, 1(2).

Piaget, J. (1960). The child's concept of the word. New Jersey: Helix Books, Rowan and Allen. 
Richaudeau, F. (1979). Conception et production des manuels scolaires. Guide pratique. Paris: Unesco.

Scott, J. (1990). A Matter of Record: Documentary Sources in Social Research. Cambridge: Polity.

Wilbraham, L. (1995). Thematic Content Anakysis: panacea for the ilis of "intentioned opacity" of discourse analysis? Presented at the $1^{\text {st }}$ Annual Qualitative Methods Conference: "A spanner in the works of the factory of truth", 20 October 1995. University of the Witwatersrand, South Africa. Retrieved from http://www.criticalmethods.org.

\section{Copyrights}

Copyright for this article is retained by the author(s), with first publication rights granted to the journal.

This is an open-access article distributed under the terms and conditions of the Creative Commons Attribution license (http://creativecommons.org/licenses/by/3.0/). 